\title{
The parent analogy: a reassessment
}

\author{
Jonathan Curtis Rutledge ${ }^{1}$
}

Received: 13 June 2016/ Accepted: 27 September 2016/Published online: 4 October 2016

(C) The Author(s) 2016. This article is published with open access at Springerlink.com

\begin{abstract}
According to the parent analogy, as a caretaker's goodness, ability and intelligence increase, the likelihood that the caretaker will make arrangements for the attainment of future goods that are unnoticed or underappreciated by their dependents also increases. Consequently, if this analogy accurately represents our relationship to God, then we should expect to find many instances of inscrutable evil in the world. This argument in support of skeptical theism has recently been criticized by Dougherty. I argue that Dougherty's argument is incomplete, for there are two plausible ways of construing the parent analogy's conclusion. I supplement Dougherty's case by offering a new argument against the parent analogy based on failed expectations concerning the amount of inscrutable evils encountered in the world. Consequently, there remains a significant empirical hurdle for skeptical theism to overcome if it is to maintain its status as a defeater for our reliability when tracking gratuitous evils.
\end{abstract}

Keywords Skeptical theism · Parent analogy $\cdot$ Evil $\cdot$ Dougherty $\cdot$ Wykstra

Defenses of skeptical theism attempt to establish two fundamental points concerning our evidence for the existence of gratuitous evil. First, they establish that we have a defeater for the reliability of such evidence, and second, they establish, by appeal to some theory of defeat, the type and degree of defeat conferred by skeptical theistic considerations.

Jonathan Curtis Rutledge

jr229@st-andrews.ac.uk

1 University of St Andrews, South Street, St Andrews KY16 9BG, United Kingdom 
In this paper, I ignore the question concerning the type and degree of defeat involved with skeptical theism. ${ }^{1}$ Instead, I focus on a particular argument for the conclusion that skeptical theism confers a defeater of some sort on anyone who entertains skeptical theism; namely, the parent analogy. I argue that the parent analogy fails in this strong aim.

In what follows, I present the parent analogy as an analogical argument ${ }^{2}$ followed by a criticism of it due to Trent Dougherty. I then go on to argue that there are two plausible interpretations of the conclusion at which skeptical theists, such as Stephen Wykstra, aim. The first interpretation, which Dougherty calls Obscurity, leads us to expect that most of the sufferings we encounter in the world would be inscrutable to us, were theism true. I call the second interpretation Obscurity Light. That thesis leads us to expect that many, rather than most, of the sufferings we encounter would be inscrutable to us, were theism true. Dougherty's criticisms, though apt, only target the stronger thesis: Obscurity. As a result, if the parent analogy is employed in support of the weaker conclusion, Obscurity Light, Dougherty's critique fails to hit its target. In other words, Dougherty's criticisms are incomplete as they stand, for they fail to address this alternative interpretation of the parent analogy. Lastly, in "The Parent Analogy Exonerated?-Deeper Issues", I supplement Dougherty's original argument by offering a new criticism of the parent analogy understood as supporting Obscurity Light. What results is a twopronged argument according to which the parent analogy fails, whether it is advanced in support of Obscurity or Obscurity Light. Thus, the fundamental goal of the parent analogy, which is to motivate the acceptance of skeptical theism as an epistemic defeater for reasonable belief in the existence of gratuitous evils, is not attained.

\section{The parent analogy}

Perhaps it is best to begin with one of the earliest statements of the parent analogy:

A modest proposal might be that [God's] wisdom is to ours, roughly as an adult human's is to a 1 month old infant's. (You may adjust the ages and species to fit your own estimate of how close our knowledge is to omniscience.) If such goods as this exist, it might not be unlikely that we should discern some of them: even a 1 month old infant can perhaps discern, in [his] inarticulate way, some of the purposes of his mother in her dealings with him. But if outweighing goods of the sort at issue exist in connection with

\footnotetext{
1 Though, for some recent and interesting discussion on this issue, see Dougherty (2014, pp. 21-31) and Matheson (2014, pp. 3-20).

${ }^{2}$ I have heard some people lament that there is no argument in favor of the parent analogy. I think this trivially true, and moreover, I think it's an odd sort of criticism since, as I understand the analogy, it is an argument. And thus, the fact that there aren't any arguments in support of the parent analogy argument is unsurprising. Arguments aren't directly supported by other arguments unless we're speaking fairly loosely. More carefully, the premises of arguments are supported by further arguments with those premises as their conclusions. Or at least, so things seem to me.
} 
instances of suffering, that we should discern most of them seems about as likely as that a 1 month old should discern most of his parents' purposes for those pains they allow him to suffer-which is to say, it is not likely at all. ${ }^{3}$

The thoughts detailed in the above paragraph derive from a very natural intuition; namely, that God's cognitive capacities vastly outrun our own and that the way in which God's cognitive capacities do this is not unlike the way in which a parent's cognitive capacities outrun the cognitive capacities of their infant children. Despite the naturalness of this thought, if we are to fully understand the parent analogy's value as an argument for skeptical theism, it is best to formulate it as a piece of analogical reasoning. ${ }^{4}$

In order to present the parent analogy as an argument, then, let us begin by identifying the four basic parts of any analogical argument. They are:

(i) the source domain $(S)$-i.e. some state of affairs with which we are familiar,

(ii) the target domain $(T)$-i.e. some state of affairs with which we are less familiar,

(iii) a set of properties $(P)$ accepted as held in common by the source and target domains, and

(iv) some further property or set of properties $(Q)$ that allegedly hold of $T$ since they are known to hold of $S$ and follow (in some relevant way) from the instantiation of $P$ in $S^{5}$

For the strongest version ${ }^{6}$ of the parent analogy, we can identify these parts of the analogical argument in the following way:

$(S)$ The state of affairs of a parent permitting the suffering of their 10 year old child $^{7}$

$(T)$ The state of affairs of God permitting our suffering

$(P)$ The following set of three properties:

(a) being such that as the guardian's degree of goodness, $G$, increases, so increases the likelihood that the guardian will make arrangements for future benefits concerning their dependents.

(b) being such that as the guardian's degree of ability, $A$, increases, so increases the likelihood that the guardian will be able to bring about

\footnotetext{
3 (Wykstra 1984, pp. 155-6).

4 In personal conversation, Linda Zagzebski has suggested that any formalized version of such analogies is less plausible than the bare analogical intuition underlying the argument. Thus, if someone were to reject the analogical argument for some reason, that same reason may not suffice for rejecting the analogy as a whole. For something similar with respect to reformed epistemology and natural theology, cf. (Evans 2012).

5 See Copi (2010) for the basic structure of analogical argumentation as I present it above. See also Ribeiro (2014) for a valuable interdisciplinary discussion of the merit of analogical argumentation.

${ }^{6}$ I'm bypassing some back-and-forth history concerning this argument by simply presenting a version of the argument that's been modified to avoid earlier criticisms.

7 Sennett (1993, p. 226) presents reasons for increasing the age of the child in question to sidestep a criticism from Rowe (1996, p. 275).
} 
whatever future-oriented arrangements they've made for their dependents.

(c) being such that as the guardian's degree of intelligence, $I$, increases, so increases the likelihood that the future-oriented goods for which the guardian has arranged will be either unnoticed or underappreciated (in terms of value) by their dependents. ${ }^{8}$

$(Q)$ being inscrutable but in fact morally permissible

To put this in analogical argument form, then, we have the Parent Analogy Argument:

1. The state of affairs of a parent permitting the suffering of their child $(S)$ is similar to the state of affairs of God permitting our suffering $(T)$ with respect to $(P)$ : (a) as $G$ increases, so increases the likelihood that a guardian will make arrangements concerning future goods for the benefit of their dependents; (b) as $A$ increases, so increases the likelihood that a guardian will succeed in bringing about their future-oriented arrangements; and (c) as $I$ increases, so increases the likelihood that such future-oriented goods will be inscrutable to dependents.

2. Oftentimes, the state of affairs of a parent permitting the suffering of their child has the further property of $(Q)$ : being inscrutable but in fact morally permissible.

3. Therefore, oftentimes the state of affairs of God permitting our suffering has the further property of $(Q)$ : being inscrutable but in fact morally permissible.

Put informally, the reasoning of the Parent Analogy Argument is as follows. The greater some guardian's degree of goodness, ability, and intelligence, the more likely it is it that the guardian will permit current suffering which is necessary for goods in the future. And the greater the disparity of intelligence of the guardian over and above the dependents, the more likely it is that these future goods will be obscure to (i.e. unnoticed or underappreciated by) the dependents. Moreover, we see this state of affairs playing out in rather mundane ways regularly, as when a parent allows their child to fail at a sport for the sake of developing tenacity or when parents withhold current luxuries from their children for the sake of saving for a college education. Children often fail to appreciate the importance of such matters, but such failed appreciation on the part of a child hardly makes us doubt the goodness and wisdom of parents. Thus, we should not doubt the goodness and wisdom of God in the face of inscrutable (i.e. apparently gratuitous) suffering any more than we doubt a parent's goodness and wisdom in relevantly similar circumstances.

\footnotetext{
${ }_{8}$ Wykstra (1996, pp. 126-51) lays out the three properties articulated in this version of the parent analogy argument.
} 


\section{Dougherty: transparency, obscurity and obscurity light}

There is a worry, however, which has been aptly stated by Trent Dougherty. He argues that what is truly at issue when assessing the parent analogy is which of the following incompatible theses is rendered more probable by the considerations of the parent analogy.

Obscurity If the world is made by an omnipotent, omniscient God, then it is highly likely that if evil is permitted, most of the goods for the sake of which it is permitted will be obscure to humans.

Transparency If the world is made by an omnipotent, omniscient God, then it is highly likely that if evil is permitted, then most of the goods for the sake of which it is permitted will be transparent to humans. ${ }^{9,10}$

Dougherty argues that if skeptical theism is to succeed in establishing that there is a defeater for the reliability of one's experience of apparently gratuitous evil when it comes to identifying actually gratuitous evil, then the parent analogy must support Obscurity over Transparency (where Obscurity is equivalent to my $Q$ in the parent analogy of the previous section). And so conversely, if the parent analogy supports the truth of Transparency over Obscurity, then skeptical theism will be in trouble. To understand why, think about which types of disputants concerning the problem of evil would support a thesis like Transparency. There are at least two types of interlocutors that come immediately to mind. First, anyone who simply finds themselves with the intuition that skeptical theism is false (i.e. what I call an 'anti-Agnostic' $)^{11}$ will likely find themselves in a position to think that Obscurity is improbable given the parent analogy. Second, anyone who defends theodicies of various sorts will likewise defend Transparency. Theodicists take themselves to be able to identify the goods (or types of goods) for the sake of which various evils are permitted, and they assume that they can do so in a reliable way (i.e. given sufficiently earnest and sustained attempts to find such goods). But to engage in the project of identifying the possible goods to which apparently gratuitous evils might lead is to engage in a project deemed likely to fail by any skeptical theist. Thus, engaging in theodicy (loosely) ${ }^{12}$ implies that one accepts Transparency.

\footnotetext{
9 (Dougherty 2012, p. 20).

${ }^{10}$ Dougherty calls this Strong Transparency. It is the thesis he is concerned with in the article, and although he states it as, "the goods for the sake of which it is permitted will usually be transparent to humans," I prefer to replace 'usually' with the, to my tastes, more lucid 'most' (Ibid., 20; italics mine). In either case, at least $50 \%$ seems to be the intended meaning.

11 In Howard-Snyder (2009, pp. 17-18), Howard-Snyder expresses his preference for the label 'Agnosticism' as a replacement for 'skeptical theism' given various misgivings with the more common label. I understand the misgivings, and at least for the purposes of identifying those who have contradictory intuitions concerning skeptical hypotheses of skeptical theism, I'll use his label with the added 'anti-' to express the point.

12 I say 'loosely' because someone might engage in theodicy as a back-up plan in case their skeptical theistic intuitions are wrong. Usually, however, such a person would, properly speaking, be engaging in defense since, as I intend to use the term, such projects do not require that we can pick out the actual goods for which some evils are permitted. Allow me, then, to simply register that I take the project of defense to be consistent with sufficiently weak construals of skeptical theism, whereas I take theodicy to
} 
Now, here is the problem as Dougherty succinctly summarizes it in terms of the above theses:

The central problem for [the skeptical theist's] expanded defense of the Parent Analogy is that even if it is true that ability to plan for the future will increase in proportion to the scale of the three properties he mentions, the probability of Transparency will also increase in proportion to the scale of those three properties. (Or at least it is at least as plausible that the latter will as that the former will.) This completely undercuts the usefulness of the Parent Analogy to support Obscurity. For the more benevolent a being, the more they would want sufferers to understand the reasons for which they are permitted to suffer. And the more wisdom they had, the more likely they would know how to do it. And the more power they had, the more likely they would be able to make it happen. ${ }^{13}$

Thus, as Dougherty understands the parent analogy, it only establishes a good argument for skeptical theism if the probability of Obscurity given the parent analogy is greater than the probability of Transparency given the parent analogy. But at best, he thinks, both theses end up equally probable given the parent analogy, and so, the argument cannot support skeptical theism over its competitors (i.e. antiAgnostics or theodicists).

I agree with Dougherty that as he's presented the argument, ${ }^{14}$ the parent analogy fails to support skeptical theism; however, there are two importantly different ways of understanding the conclusion of the parent analogy. The first way, which Dougherty adopts, is to equate the conclusion with Obscurity. The second way of understanding the conclusion, however, is subtly (though not insignificantly) different. Consider the following premise from Stephen Wykstra (i.e. Dougherty's main interlocutor and the primary defender of the parent analogy), which most closely resembles Obscurity:

Obscurity Light-It is likely that the goods for which O [i.e. an omni-God] permits many sufferings are beyond our ken. ${ }^{15}$

Footnote 12 continued

not be similarly consistent. For an example of an author who uses 'theodicy' as equivalent to my use of 'defense', see Hasker (2011, p. 302).

13 Dougherty, "reconsidering the parent analogy," 23.

14 It is perhaps worth pointing out that Dougherty's criticisms of the parent analogy are importantly different from William Rowe's-see Rowe, "The Evidential Argument from Evil: A Second Look," 275-276, (Rowe 2001, pp. 130-131). The first difference is this: Rowe's reverse parent analogy proceeds from the set of all inscrutable evils, whereas Dougherty and the original parent analogy argument proceed from the set of all evils. Thus, Rowe is presenting an altogether different argument rather than contesting the conclusion of the first argument. The second difference is this: Dougherty takes the considerations of the parent analogy to simply support the negation of the intended conclusion of the original parent analogy, whereas Rowe concerns himself in the reverse parent analogy with a conclusion concerning God's offering assurance of love to the one suffering. What's really happening in Rowe, then, is that he's not really criticizing the original parent analogy, but rather, redirecting us to a different argument. Dougherty prefers to remain focused on the merit, or lack thereof, of the original argument.

15 Wykstra, "Rowe's Noseeum Arguments from Evil," 140; italics are mine. In Wykstra's text, this thesis is simply called (2). I've renamed it 'Obscurity Light' to avoid confusion in my text. 
And now, compare Wykstra's Obscurity Light with Dougherty's Obscurity:

Obscurity - If the world is made by an omnipotent, omniscient God, then it is highly likely that if evil is permitted, most of the goods for the sake of which it is permitted will be obscure to humans. ${ }^{16,17}$

Notice the presence of the word 'many' in Obscurity Light. Wykstra is not necessarily claiming that we should expect most of the evils we encounter to be inscrutable as Obscurity states. His claim, and the claim of skeptical theists, is plausibly much weaker. They only require that many of the evils encountered in the world turn out to be inscrutable. And this is not insignificant, for if Obscurity Light indeed represents the intended conclusion of the parent analogy, then Dougherty's claim that Transparency is more probable than Obscurity will be beside the point, for while Obscurity is inconsistent with Transparency, Obscurity Light is not. And thus, even if Dougherty is correct to think that Transparency is supported by the considerations advanced in the parent analogy, Obscurity Light could simultaneously be well supported by those same considerations.

Moreover, Obscurity Light does seem reasonably well supported by the parent analogy, for surely there would be some cases, as I suggested earlier, where children simply fail to appreciate the value of some future good for which they are currently suffering, even if most of the time such children do see the reasons for which their parents permit their suffering. As a result, as long as we can think of at least two dozen (or so... $)^{18}$ instances of this sort of arrangement, then that would suffice to justify the analogical argument Wykstra advances in support of Obscurity Light, even if Transparency were well supported as well.

So what does this alternative interpretation of the strength of the parent analogy's conclusion imply concerning Dougherty's argument? Only that his argument is incomplete, for it is not entirely unreasonable to read Wykstra's description of the parent analogy as supporting the stronger thesis, Obscurity, ${ }^{19}$ and if a skeptical theist were to advance the parent analogy in this way, then Dougherty's criticisms would indeed be apt. However, for Dougherty's criticisms to fully remove the power of the parent analogy to motivate skeptical theism, further scrutiny must be directed towards an Obscurity Light construal of the parent analogy. To this we now turn.

\footnotetext{
16 I've added the italics to bring out the salient contrast.

17 It is worth reminding ourselves that there are several cognitive limitations that might render an evil inscrutable from the perspective of an individual. One important such limitation manifests when an agent fails to realize that a token good belongs to some good-type that would be sufficient to morally justify the permission of the relevant evil. For an earlier articulation of this point, see Alvin Plantinga, "Epistemic Probability and Evil," Archivo di filosofia 56 (1988): 557-84; Reprinted in Howard-Snyder, Daniel (ed.) The Evidential Argument from Evil (Bloomington, IN: Indiana University Press, 1996): 69-96.

18 For the phrase, see Plantinga (2007, pp. 203-228) for the inspiration.

19 Simply reread the Wykstra quotation at the start of this section and ask yourself whether Obscurity or Obscurity Light best explains the way in which Wykstra frames the parent analogy there.
} 


\section{The parent analogy exonerated?-deeper issues}

As I have represented Dougherty's argument, it leaves a way out for proponents of the parent analogy. Nevertheless, this apparent way out does not come without some serious difficulties, which I detail in this final section. In brief, I offer an argument against the adequacy of the parent analogy to motivate skeptical theism due to the problem of failed expectations.

In my experience, the sufferings of this world are commonly inscrutable. Indeed, sufferings ranging from interpersonal rudeness to overwhelming systemic injustices seem largely inscrutable most of the time. Thus, if skeptical theism is to succeed in addressing the worries articulated by various forms of the evidential argument from evil for me, $I$ would need not only a reason to expect that many sufferings would be inscrutable given theism, but also a reason to expect that most sufferings would be inscrutable given theism. Thus, even if the parent analogy succeeds in supporting the truth of Obscurity Light, skeptical theism fails to be a live option for me on such a meager basis. For given my own background evidence, there is a mismatch between what the parent analogy leads me to expect (i.e. that no more than many sufferings would be inscrutable, given theism) and what I actually find when consulting my evidence (i.e. that most suffering falls within the inscrutable variety). The following, then, is an argument that someone with similar reflections to my own might readily endorse, one which renders the parent analogy unhelpful under the Obscurity Light construal:

A. If the parent analogy is sufficient to motivate skeptical theism and theism is true, then the world we live in is nothing more than an Obscurity Light world.

B. But our world is an Obscurity world (i.e. more than an Obscurity Light world).

C. Therefore, either the parent analogy does not suffice to motivate skeptical theism or theism is false.

My reflections above concerning the amount of inscrutable evil support the truth of (B). Moreover, (A) is implicitly accepted by skeptical theists such as Wykstra. ${ }^{20}$ So, if a skeptical theist wants to respond to this argument, she should do so by consulting her own acquaintance with the quantity and distribution of inscrutable evil in the world. And perhaps if she does so, she will find that, in her own experience, (B) is false. That is, perhaps a skeptical theist will find that her evidence concerning the amount of inscrutable evil is simply different from my evidence concerning inscrutable evil, and if this is so, then she would surely be epistemically rational in accepting the parent analogy.

However, this conclusion should hold little comfort for the skeptical theist. Firstly, the parent analogy stands as the only positive argument for accepting

\footnotetext{
${ }^{20}$ Perhaps someone might resist this and claim that skeptical theists, in some cases, do want to support Obscurity, rather than just Obscurity Light, on the basis of the parent analogy, as noted above. If someone were to take this road, then Dougherty's argument would become relevant since this is just the sort of person he was originally targeting.
} 
skeptical theism as a defeater for the reliability of our experiences of inscrutable evil as trackers of gratuitous evil. Thus, if it fails, then skeptical theists have no positive reason for assenting to the theses they advance. ${ }^{21}$ Secondly, notice that the above argument can be run without committing to the truth or falsity of the characteristic skeptical theist's claim that experiences of inscrutable evil are evidentially irrelevant to whether or not an evil is gratuitous. The evidence for the truth of (B) concerns our ability to pick out inscrutable evil rather than our ability to pick out gratuitous evil, and plausibly, we have the best access available (or at least, sufficiently good access) to whether evils are inscrutable to us. As a result, the argument cannot be rightly criticized for begging the question against skeptical theism.

What can be gleaned from all this? Fundamentally, this shows that whether or not skeptical theism can be sufficiently motivated for an individual will depend on some personal and honest reflection concerning the amount of inscrutable suffering in the world. Perhaps this will allow some individuals to rationally accept skeptical theism on the basis of the parent analogy, but given the way the world actually is, it seems unlikely that many people would be able to adopt skeptical theism on that basis. As a result, even though Dougherty's argument fails to undermine the parent analogy on its own, when supplemented by the above considerations concerning failed expectations, there remains a significant empirical hurdle for skeptical theists to overcome.

\section{Conclusion}

In this paper, I argued that Dougherty's criticism of the parent analogy was incomplete since it only addressed one of two reasonable interpretations of the strength of the conclusion of the parent analogy. After highlighting the difference between these two interpretations of the parent analogy, Obscurity and Obscurity Light, I advanced my own criticism of the latter interpretation concerning the problem of failed expectations. According to that criticism, while it is possible for some philosophers (e.g. Wykstra) to expect a low degree of inscrutable evil and find evidence matching that expectation, in most cases, the parent analogy leads to a mismatch between (i) the way one would expect the world to appear, given theism and (ii) how the world actually appears. For those who perceive such a mismatch, there must either be other considerations yet unrevealed in support of skeptical theism or they should give up the view altogether. ${ }^{22}$

\footnotetext{
21 Or at least, skeptical theists will not have any positive argument for accepting those theses. Whether or not they might have a reason depends on further considerations dealing with rationality that are beyond the scope of this paper.

22 I would like to thank an anonymous referee whose feedback resulted in a much improved paper.
} 
Open Access This article is distributed under the terms of the Creative Commons Attribution 4.0 International License (http://creativecommons.org/licenses/by/4.0/), which permits unrestricted use, distribution, and reproduction in any medium, provided you give appropriate credit to the original author(s) and the source, provide a link to the Creative Commons license, and indicate if changes were made.

\section{References}

Copi, I. (2010). Introduction to logic (14th ed.). New York: Routledge Publishing.

Dougherty, T. (2012). Reconsidering the parent analogy: Unfinished business for skeptical theists. International Journal for Philosophy of Religion, 72(1), 17-25.

Dougherty, T. (2014). Phenomenal conservatism, skeptical theism, and probabilistic reasoning. In T. Dougherty \& J. P. McBrayer (Eds.), Skeptical theism: New essays (pp. 21-31). Oxford: Oxford University Press.

Evans, C. S. (2012). Natural signs and knowledge of god. Oxford: Oxford University Press.

Hasker, W. (2011). An open theist theodicy of natural evil. In K. Perszyk (Ed.), Molinism: The contemporary debate (pp. 281-302). Oxford: Oxford University Press.

Howard-Snyder, D. (2010). Epistemic humility, arguments from evil, and moral skepticism. In J. Kvanvig (Ed.), Oxford studies in philosophy of religion (pp. 17-57). Oxford: Oxford University Press.

Matheson, J. (2014). Phenomenal conservatism and skeptical theism. In T. Dougherty \& J. P. McBrayer (Eds.), Skeptical theism: New essays (pp. 3-20). Oxford: Oxford University Press.

Plantinga, A. (2007). Appendix: Two dozen (or so) theistic arguments. In D. P. Baker (Ed.), Alvin Plantinga (pp. 203-228). Cambridge: Cambridge University Press.

Ribeiro, H. J. (2014). Systematic approaches to argument by analogy. New York: Springer.

Rowe, W. L. (1996). The evidential argument from evil: A second look. In D. H. Snyder (Ed.), The evidential argument from evil (pp. 262-285). Bloomington, IN: Indiana University Press.

Rowe, W. L. (2001). Grounds for belief aside, does evil make atheism more reasonable than theism. In W. E. Mann (Ed.), God and the problem of evil (pp. 124-137). Malden, MA: Blackwell Publishing.

Sennett, J. F. (1993). The inscrutable evil defense against the inductive argument from evil. Faith \& Philosophy, 10, 220-229.

Wykstra, S. (1984). The humean obstacle to evidential arguments from suffering: On avoiding the evils of 'appearance'. International Journal for Philosophy of Religion, 16, 73-93.

Wykstra, S. (1996). Rowe's noseeum arguments from evil. In D. Howard-Snyder (Ed.), The evidential argument from evil (pp. 126-151). Bloomington, IN: Indiana University Press. 